\title{
Proposed Minimal Standards for Description of New Taxa in the Order Halobacteriales
}

\author{
A. OREN,${ }^{1 *}$ A. VENTOSA, ${ }^{2}$ AND W. D. GRANT ${ }^{3}$ \\ The Alexander Silberman Institute of Life Sciences and The Moshe Shilo Center for Marine Biogeochemistry, \\ The Hebrew University of Jerusalem, 91904 Jerusalem, Israel $^{1}$; Departamento de Microbiologia y \\ Parasitologia, Facultad de Farmacia, Universidad de Sevilla, 41012 Seville, Spain ${ }^{2}$; and \\ Department of Microbiology and Immunology, University of Leicester, \\ Leicester LE1 9HN, United Kingdom ${ }^{3}$
}

\begin{abstract}
In accordance with Recommendation 30b of the International Code of Nomenclature of Bacteria, which calls for the development of minimal standards for describing new species, we propose minimal standards for description of new taxa in the order Halobacteriales. The minimal standards include information on the following characteristics: cell morphology; motility; pigmentation; the requirement for salt to prevent cell lysis; optimum $\mathrm{NaCl}$ and $\mathrm{MgCl}_{2}$ concentrations for growth and range of salt concentrations enabling growth; temperature and pH ranges for growth; anaerobic growth in the presence of nitrate or arginine; acid production from a range of carbohydrates; ability to grow on single carbon sources; catalase and oxidase tests; hydrolysis of starch, casein, and Tween 80; sensitivity to different antibiotics; and polar lipids. The placement of a new taxon should be consistent with phylogeny, which is usually based on 16S rRNA nucleotide sequence information, and with DNA-DNA hybridization data in the case of descriptions of new species. This proposal has been endorsed by the members of the Subcommittee on the Taxonomy of Halobacteriaceae of the International Committee on Systematic Bacteriology.
\end{abstract}

In accordance with Recommendation $30 \mathrm{~b}$ of the International Code of Nomenclature of Bacteria (21), which calls for the development of minimal standards for describing new species, we propose minimal standards for descriptions of new taxa of aerobic halophilic archaea (order Halobacteriales).

General principles. The purpose of this article is to provide microbiologists involved in the taxonomy of the aerobic halophilic archaea (order Halobacteriales, family Halobacteriaceae; also called halobacteria below) a framework for studying them. Adherence to the suggested minimum standards below should help stabilize the taxonomy of the Halobacteriales. With the consent and support of the Subcommittee on the Taxonomy of Halobacteriaceae we have adopted a polyphasic view of halophile taxonomy as suggested by Murray et al. (26). We recommend that all future taxonomic publications on the Halobacteriales should contain data on phenetic, chemical, and molecular properties. We thus recognize that modern natural classification requires as complete a data set as possible, including phenotypic and genotypic information.

Table 1 provides a list of the presently recognized genera and species in the Halobacteriales. The current classification is based on the following three kinds of data: (i) phenotypic data, such as cell morphology, growth properties, etc. (34); (ii) chemical data, especially the patterns of polar lipids present in the membranes $(34,36)$ (differences in polar lipid patterns have been particularly important at the genus level); and (iii) 16S rRNA sequence information and DNA-DNA hybridization data. During the last few years a fairly complete database of 16S rRNA sequences of the type strains of the species in the Halobacteriales has become available and has enabled the con-

* Corresponding author. Mailing address: Division of Microbial and Molecular Ecology, Institute of Life Sciences, The Hebrew University of Jerusalem, 91904 Jerusalem, Israel. Phone: 972-2-6584951. Fax: 972-2-6528008. E-mail: orena@shum.cc.huji.ac.il. struction of a phylogenetic tree $(17,24)$. This tree is supported by DNA-DNA hybridization data and by relationships derived from numerical taxonomy distance matrices based on phenotypic data.

The subcommittee proposes that placement of a new taxon should preferentially be consistent with phylogeny, which is usually based on nucleic acid sequences. The phenetic differences within the group are relatively small because of the relatively conserved halobacterial phenotype. The sequences represented in rRNAs provide the only resource so far recognized for both discerning and testing phylogenetic associations that has the appropriate qualities of universality, genetic stability, and conservation of structure (26). However, differences in evolutionary rates in various groups of organisms prevent the use of phylogenetic parameters alone in delineating taxa. Therefore, the integrated use of phylogenetic and phenotypic characteristics, known as polyphasic taxonomy is necessary for the delineation of taxa at all levels from kingdom to genus. When workers are discriminating between closely related species of the same genus, DNA-DNA hybridization should be the method of choice, in accordance with the proposed molecular definition of species (26).

It is preferable to base descriptions of new species on characteristics of as many isolates as possible; these isolates should be obtained from different locations, and a diverse selection of them should be preserved as reference strains. For long-time preservation storage in liquid nitrogen, freeze-drying, or storage at $-80^{\circ} \mathrm{C}$ on ceramic or plastic beads is recommended. Preservation methods for halobacteria have been described by Tindall (34). One strain of each species, preferably the strain that most closely resembles the hypothetical median strain, should be designated the type strain. According to Rule $18 \mathrm{a}$ of the Bacteriologial Code (21), all newly described bacterial taxa must be represented by a type culture deposited in a permanent culture collection.

In addition, descriptions of new taxa of Halobacteriales 
TABLE 1. Presently recognized genera and species of aerobic halophilic archaea (order Halobacteriales, family Halobacteriaceae $)^{a}$

\begin{tabular}{l} 
Species \\
\hline Genus Halobacterium \\
Halobacterium salinarum \\
Genus Halorubrum \\
Halorubrum saccharovo- \\
rum \\
Halorubrum sodomense \\
Halorubrum lacusprofundi \\
Halorubrum trapanicum \\
Halorubrum distributum \\
Halorubrum coriense
\end{tabular}

Genus Haloarcula

Haloarcula vallismortis

Haloarcula marismortui

Haloarcula japonica

Haloarcula hispanica

Genus Haloferax

Haloferax volcanii

Haloferax denitrificans

Haloferax gibbonsii

Haloferax mediterranei

Genus Halobaculum

Halobaculum gomorrense

Genus Natrialba

Natrialba asiatica

Genus Halococcus

Halococcus morrhuae

Halococcus saccharolyticus

Halococcus turkmenicus

Halococcus salifodinae

Genus Natronobacterium

Natronobacterium gregoryi

Natronobacterium pharaonis

Natronobacterium magadii

Natronobacterium vacuolatum

Genus Natronococcus

Natronococcus occultus

ATCC 17082

ATCC 49257

VKM B-1734

ATCC 51437

Saltern, Spain

Saline soil, USSR

Salt mine, Austria

\section{ATCC 43098 Lake Magadi, Kenya}

ATCC 35678 Wadi Natrun, Egypt

ATCC $43099 \quad$ Lake Magadi, Kenya

NCIMB 13189 Lake Magadi, Kenya

\section{ATCC $43101 \quad$ Lake Magadi, Kenya} Lake Magadi, Kenya

\footnotetext{
${ }^{a}$ For additional data on culture collection holdings, strain histories, etc., see references $9,17,24$, and 34 .

${ }^{b}$ Halorubrum trapanicum NRC 34021 is not available. The present taxonomic status of the species is uncertain.
}

should be based on the following principles: (i) type strains of related taxa should be included for comparison, and it is recommended that in addition at least one species from each of the recognized genera (Table 1) be used for comparative purposes in studies of new isolates; (ii) the characters that differentiate each new taxon from all previously described species should be adequately described, and it is recommended that the new taxon should be able to be identified and differentiated by methods available outside specialized laboratories; (iii) the methods used must be given in detail, or references to readily available publications must be given; and (iv) the description of

each new taxon should be published in a journal that has wide circulation, preferably the International Journal of Systematic Bacteriology, and when described elsewhere, the new taxon should be included as soon as possible on one of the lists that validate the publication of new names and new combinations previously effectively published outside the International Journal of Systematic Bacteriology that appear periodically in that journal.

The subcommittee proposes the characters described below and listed in Table 2 as minimum features that should be contained in descriptions of new halobacterial taxa. However, we recognize that description of extraordinary microorganisms may require flexibility in the application of the tests described below. The proposal below specifies the minimal requirement for tests and does not in any way limit the extent of investigations beyond this.

Morphology and growth characteristics. The phenotypic characteristics of the Halobacteriales are, perhaps more than

TABLE 2. Minimal standards for description of halobacterial taxa

\begin{tabular}{ll}
\hline Importance & \multicolumn{1}{c}{ Minimal standards } \\
\hline Required & Colonial morphology \\
Cell morphology & Motility \\
& Pigmentation \\
& Gram stain \\
Salt concentrations required to prevent cell lysis & Optimum NaCl and $\mathrm{MgCl}_{2}$ concentrations for growth \\
& Range of salt concentrations enabling growth \\
& Temperature and pH ranges for growth \\
Anaerobic growth in the presence of nitrate & Reduction of nitrate to nitrite \\
Formation of gas from nitrate \\
Anaerobic growth in the presence of arginine \\
Production of acids from a range of carbohydrates \\
Ability to grow on a range of single carbon sources \\
Catalase and oxidase activities \\
Formation of indole \\
Starch hydrolysis \\
Gelatin hydrolysis \\
Casein hydrolysis \\
Tween 80 hydrolysis \\
Sensitivity to different antimicrobials (novobiocin, \\
bacitracin, anisomycin, aphidicolin, erythromycin, \\
penicillin, ampicillin, rifampin, chloramphenicol, \\
neomycin) \\
Characterization of polar lipids: \\
Types of glycolipids present \\
Presence or absence of phosphatidylglycerosulfate \\
G+C content of DNA \\
16S rRNA nucleotide sequence information \\
DNA-DNA hybridization with related species (for de- \\
scriptions of new species only) \\
\end{tabular}

Recommended Electron microscopy

Anaerobic growth in the presence of DMSO or TMAO

Phosphatase activity

Urease activity

$\beta$-Galactosidase activity

Lysine decarboxylase activity

Ornithine decarboxylase activity

Presence of glycoprotein in the cell envelope

Presence of PHA

Presence of plasmids

Electrophoresis of cellular proteins 
the phenotypic characteristics of other bacteria, greatly affected by growth conditions. Consequently, we suggest that conditions that support maximal growth rates for each strain be established before phenotypic testing is begun and that tests be performed with cells grown under optimal conditions. No single medium supports growth of all representatives of the Halobacteriales. Media for the growth of Natronobacterium and Natronococcus species are characterized by their high $\mathrm{pH}$ values and low divalent ion concentrations. Compilations of recipes for media used to grow halobacteria are found in references 20 and 34. For the preparation of solidified media agar may be added at a concentration of 15 to $20 \mathrm{~g} /$ liter.

Guidelines for phenotypic characterization of halobacteria can be found in many papers $(3,5,36,37)$. Colonial morphology should be described by using standard microbiological criteria, with special emphasis on pigmentation, diameter, colonial elevation, consistency, and opacity. These characters should be described for cultures grown at the optimum temperature, $\mathrm{pH}$, and salt concentration, and the growth medium and incubation conditions should be specified. However, colonial pigmentation and morphology should be studied preferably on media containing different salt concentrations.

Cell morphology should be examined by phase-contrast microscopy of exponentially growing liquid cultures, and the growth conditions should be specified, as cell morphology often depends on the composition of the medium, especially its magnesium content. Microscopic observations should be made by using freshly prepared wet mounts, since most non-saltcontaining bacteriological stains cause deformation or lysis of the cells and wet mounts are most appropriate for the assessment of cell motility. The halobacteria produce an astonishing array of cellular sizes and shapes, described as rods, cocci, discs, squares, or box-shaped cells. Many members of the Halobacteriales exhibit extreme pleomorphism, but strains should not be described as pleomorphic until cells grown in the presence of a wide range of salinities and magnesium concentrations have been examined. Gas vesicles appear as phasebright inclusions inside the cells. However, as production of gas vesicles is a character that is easily lost in culture, no great weight should be placed on the presence or absence of gas vesicles. Light microscopic observations may be supplemented by electron microscopy (thin sections and/or negatively stained preparations). Electron microscopic examination of negatively stained preparations (e.g., preparations stained with $0.5 \%$ uranyl acetate in $25 \% \mathrm{NaCl}$ for $30 \mathrm{~s}$ ) may supply information on flagellar arrangement in motile strains.

Gram staining should be performed by using the variation described by Dussault (4), in which air-dried slides are fixed and simultaneously desalted in $2 \%$ acetic acid for $5 \mathrm{~min}$ and then dried and stained, using standard procedures. Most halobacteria tested thus far stain gram negative; some exceptions are Halococcus spp. (gram positive) and Natronococcus spp. (gram variable).

Many members of the Halobacteriales require high salt concentrations for structural stability. Most noncoccoid forms lyse in the presence of $\mathrm{NaCl}$ concentrations below $10 \%$, but halococci may be very resistant to lysis or may not lyse at all. The salt requirement for maintaining stability of the cell envelope should be determined by suspending cells in decreasing concentrations of a salt solution with the salt composition of the optimal culture medium. Lysis of cells can be detected by a loss of turbidity of the suspension and/or by microscopic examination. Certain Haloferax and Haloarcula species require relatively high divalent cation concentrations in addition to a high overall salinity to maintain their native pleomorphic shape, and lowering the magnesium concentration to values below $50 \mathrm{mM}$ may lead to the immediate formation of spheroplasts, even in the presence of high $\mathrm{NaCl}$ concentrations (2). Thus, the specific requirement for divalent cations to maintain native cell morphology should be examined in addition to the overall salt requirement.

For each strain the optimal $\mathrm{NaCl}$ and $\mathrm{MgCl}_{2}$ concentrations, $\mathrm{pH}$, and growth temperature should be determined, together with the ranges that permit growth. It is recommended that the optimal $\mathrm{NaCl}$ concentration be determined first, and subsequent tests for other growth parameters should be performed at the optimal $\mathrm{NaCl}$ concentration. Growth experiments should be performed in liquid media, and good aeration should be provided since oxygen solubility decreases with increasing salt concentration. Growth rates may be quantitated by determining the increase in culture turbidity. The effects of different $\mathrm{NaCl}$ concentrations on culture growth should be examined in the presence of magnesium at the concentration in the optimal growth medium and at the optimum temperature. Because the optimum $\mathrm{NaCl}$ concentration for growth of certain strains and the range of $\mathrm{NaCl}$ concentrations tolerated is temperature dependent, it is desirable to test for the effect of $\mathrm{NaCl}$ at different temperatures. The effects of different magnesium concentrations should be assessed at the optimal $\mathrm{NaCl}$ concentration. Growth experiments at high magnesium concentrations are not required for alkaliphilic strains because of the limited solubility of magnesium at high $\mathrm{pH}$ values. To examine the effect of $\mathrm{pH}$ on growth, the medium with the optimal salt concentration and composition should be supplemented with suitable buffers to maintain stable $\mathrm{pH}$ values.

Nutrition. All members of the Halobacteriales are aerobes, but many are able to grow anaerobically by using alternative electron acceptors, such as nitrate (23), dimethyl sulfoxide (DMSO), or trimethylamine $N$-oxide (TMAO) (30), or by fermenting L-arginine (11). We propose that tests for anaerobic growth on nitrate and arginine should be included in the list of minimal standards for descriptions of members of the Halobacteriales and recommend that the use of DMSO and TMAO as electron acceptors should also be tested. Growth with nitrate as the electron acceptor is tested as described by Mancinelli and Hochstein (23), and formation of nitrite from nitrate can be assessed colorimetrically. To test for anaerobic growth on arginine, DMSO, or TMAO, test tubes are filled to the top with the appropriate growth medium supplemented with 2.5 to $5 \mathrm{~g}$ of L-arginine- $\mathrm{HCl}$, DMSO, or TMAO per liter, inoculated, and closed. It is recommended that a suitable buffer be included to prevent drastic changes in $\mathrm{pH}$. Tubes are incubated in the dark at the optimal growth temperature. After 5 to 7 days the turbidity of the cultures is compared with the turbidity obtained without an added electron acceptor or arginine (30).

The range of substrates used as carbon and energy sources should be assessed in media that have concentrations of complex carbon sources such as yeast extract that are reduced to $0.1 \mathrm{~g} /$ liter or less (35). A buffer should be included in the medium, because metabolism of sugars may result in the formation of acids. It is recommended that $0.5 \mathrm{~g}$ of $\mathrm{NH}_{4} \mathrm{Cl}$ $\left(\mathrm{NaNO}_{3}\right.$ for the alkaliphiles) per liter and $0.05 \mathrm{~g}$ of $\mathrm{KH}_{2} \mathrm{PO}_{4}$ per liter be added to avoid depletion of nitrogen and phosphorus. The substrates assayed may include compounds such as glucose, mannose, galactose, fructose, D-ribose, D-xylose, maltose, sucrose, lactose, starch, glycerol, mannitol, sorbitol, acetate, pyruvate, DL-lactate, succinate, L-malate, fumarate, citrate, glycine, L-alanine, L-arginine, L-aspartate, L-glutamate, L-lysine, and others. Production of acid from the above-mentioned carbohydrates and sugar alcohols is tested in unbuffered 
growth medium supplemented with $0.5 \mathrm{~g}$ of a substrate per liter. Phenol red may be used as an indicator to detect acid production, or the $\mathrm{pH}$ of the cultures may be measured with a glass electrode at the end of the incubation period and compared with the initial $\mathrm{pH}$ and the $\mathrm{pH}$ of a control tube without added substrate.

Certain members of the Halobacteriales have been reported to grow on defined media with a single carbon and energy source. Growth on single carbon sources should be tested by using either liquid medium or medium solidified with highly purified agar with the salt composition of the optimal growth medium and supplemented with $\mathrm{NH}_{4} \mathrm{Cl}$ or $\mathrm{NaNO}_{3}$ as required, $\mathrm{KH}_{2} \mathrm{PO}_{4}$, the compound to be tested at a concentration of $1 \%$, and buffer. To avoid false-positive results due to carryover of nutrients from the inoculum, a strain is considered as growing on a defined carbon source only if growth is maintained after continued serial transfer.

Miscellaneous biochemical tests. The following tests are included in the minimal standards: tests for catalase, oxidase, formation of indole, and hydrolysis of starch, gelatin, casein, and Tween 80 . In addition, we recommend that phosphatase, urease, $\beta$-galactosidase, and lysine and ornithine decarboxylase activities be tested. Biochemical testing of halophiles generally does not require special media or techniques except that the medium must contain the optimal ionic content. Therefore, standard biochemical test methods may be used $(3,5,14,37)$. Hydrolysis of Tween 80 (esterase activity) and hydrolysis of gelatin (protease activity) can be tested simultaneously by using the procedure adapted for halobacteria by Gutierrez and Gonzalez (7). Positive and negative controls should be included when these tests are performed.

Sensitivity to antimicrobial agents. Information on sensitivity to the following antibiotics and other antibacterial agents should be included in descriptions of new taxa of halobacteria: novobiocin, bacitracin, anisomycin, aphidicolin, erythromycin, penicillin, ampicillin, rifampin, chloramphenicol, and neomycin. Ideally, the substances to be tested should be added to liquid media at concentrations of 25 to $50 \mu \mathrm{g} / \mathrm{ml}$. Alternatively, tests may be performed by spreading bacterial suspensions on plates containing the appropriate growth medium and applying disks impregnated with the antimicrobial agents. It is recommended that additional compounds, such as the quinolone derivatives norfloxacin and ciprofloxacin be tested. Information on the sensitivity of different halophilic archaea to antibiotics has been given by Tindall (34) and by other authors $(1,13,31)$

Lipids, cellular proteins, and structure of the cell envelope. Lipid analysis has been particularly useful in the characterization of different taxa of the Halobacteriales, and any description of a new species should include a characterization of polar lipids, with special emphasis on the pattern of the glycolipids present and the presence or absence of the diether derivative of phosphatidylglycerosulfate. The lipids most commonly found in the halobacteria consist of phytanyl or sesterterpanyl ether analogs of phosphatidylglycerol, phosphatidylglycerophosphate, and phosphatidylglycerosulfate. The types of glycolipids present are characteristic for the different genera (with the exception of the genus Halorubrum), and phosphatidylglycerosulfate is absent in representatives of the genera Haloferax and Halobaculum $(6,17,18,24,29,34)$. There is little evidence that the polar lipid composition of halobacteria changes according to the growth conditions, with one possible exception: a Halococcus strain was found to contain an unidentified triglycoside diglyceride as the major glycolipid when it was grown at $34^{\circ} \mathrm{C}$, but a diglyco- side diglyceride was found in major amounts when it was grown at $20^{\circ} \mathrm{C}(15)$.

Polar lipid patterns are easily assessed by one- or two-dimensional thin-layer chromatography $(28,36)$. Some strains have $\mathrm{C}_{20} \mathrm{C}_{20}$ and $\mathrm{C}_{20} \mathrm{C}_{25}$ core lipids. This can usually be seen by the phosphatidylglycerol separating into two spots and can be confirmed by thin-layer chromatography after acid methanolysis by using a double development procedure (32).

Certain halobacteria produce intracellular granules of poly$\beta$-hydroxyalkanoate (PHA) as a storage polymer when they are grown under appropriate growth conditions (22). The polymer can be detected microscopically by fixing smears with $2 \%$ acetic acid for 5 min, drying, staining with $0.3 \%$ Sudan black in $70 \%$ ethanol for $10 \mathrm{~min}$, washing with xylene, and counterstaining with saffranin. A quantitative colorimetric assay to determine the PHA contents of halobacteria has been described as well (22). The presence or absence of PHA has not been included in most species descriptions thus far, and because production of the polymer may be highly dependent on growth conditions, we recommend that the test for PHA be optional.

Electrophoresis of cellular proteins has been used to differentiate between taxa of the Halobacteriales (12). We recommend that this procedure be included for descriptions of taxa below the genus level.

The cell envelope of noncoccoid halobacteria consists of glycoprotein subunits, while the halococci lack this component and possess a complex polysaccharide cell wall instead. We recommend that the presence of glycoprotein in the cell envelope be tested for by performing polyacrylamine gel electrophoresis of isolated cell envelopes, followed by specific staining (25).

Nucleic acid characterization. Descriptions of new members of the Halobacteriales should contain information on the $\mathrm{G}+\mathrm{C}$ contents of their DNAs and the nucleotide sequences of their $16 \mathrm{~S}$ rRNAs. DNA base composition may be determined by any of the commonly used techniques, such as ultracentrifugation in a $\mathrm{CsCl}$ gradient, thermal denaturation, or high-performance liquid chromatography of nucleotides after hydrolysis. The method used should be included in the description. When feasible, $\mathrm{CsCl}$ equilibrium centrifugation is the method of choice, because it allows the detection of any additional DNA component that may be present (satellite DNA, megaplasmids) with a $\mathrm{G}+\mathrm{C}$ content different from that of the chromosomal DNA.

Many halophilic archaea contain plasmids, and it is recommended that information on the presence and sizes of plasmids be included. However, plasmids are often easily lost, and thus no great importance can be attached to their presence or absence. The detection of megaplasmids may require special methods (8).

Information on the $16 \mathrm{~S}$ rRNA nucleotide sequence is considered essential to determine the phylogenetic position of new isolates. A fairly complete database of 16S rRNA sequences is now available for halobacteria $(17,19,24,29)$, and phylogenetic distances based on 16S rRNA sequences show excellent correlation with phenetic and chemical data. The presence of more than one gene for $16 \mathrm{~S}$ rRNA may cause sequence heterogeneity within a strain $(19,27)$ and may require determination of all sequences. Determination of $16 \mathrm{~S}$ rRNA sequences may be performed by direct sequencing of enzymatically amplified DNA with specific oligonucleotide primers or by reverse transcription of purified 16S rRNA followed by sequencing of the DNA transcript. Sequences should be deposited in a database, the database records, as well as publications, must include an unequivocal statement of the 
identity of the source strain, as well as methodological data, and the accession number must be included in the species description.

The Ad Hoc Committee on Reconciliation of Approaches to Bacterial Systematics agreed on a bacterial species definition supported by the results of DNA-DNA hybridization studies (38). Such studies make use of the renaturation properties of DNA strands that are separated by heating. Closely related DNA strands are able to reanneal and form thermostable heteroduplexes, whereas distantly related DNAs yield low percentages of homology. DNA homology studies can be used to assess relationships only within narrow ranges of variation as homology values fall to quite low levels (less than $30 \%$ ) for species that are only moderately different phenotypically. According to the Ad Hoc Committee on Reconciliation of Approaches to Bacterial Systematics, the criteria that should be used for species definition are 70 to $100 \%$ DNA relatedness and differences in the denaturation temperatures of homo- and heteroduplexes of less than $5^{\circ} \mathrm{C}(38)$. Hybridization levels equal to or greater than $70 \%$ may be considered indicative of species levels of similarity $(9,10)$.

DNA-DNA hybridization has not been widely used in studies on halobacteria, and different methods, including S1 nuclease treatment (33) and competition methods $(9,10,17)$, were employed in those few studies in which the technique was included. References 16 and 37 supply additional information on the methods available. In agreement with the presently accepted criteria for the delineation of species, we consider DNA-DNA hybridization studies to be essential when new species are described, especially for comparisons of closely related taxa. In view of the fact that workers have had little experience in the past in determining the method of choice, the subcommittee does not recommend a method at the present time. It is essential that the method used be described in each study.

We thank the following members of the Subcommittee on the Taxonomy of Halobacteriaceae for their careful reading of the manuscript and their helpful comments: R. R. Colwell, L. I. Hochstein, M. Kamekura, D. J. Kushner, C. D. Litchfield, A. RamosCormenzana, F. Rodriguez-Valera, B. J. Tindall, H. G. Trüper, and R. H. Vreeland.

\section{REFERENCES}

1. Bonelo, G., A. Ventosa, M. Megias, and F. Ruiz-Berraquero. 1984. Th sensitivity of halobacteria to antibiotics. FEMS Microbiol. Lett. 21:341 345

2. Cohen, S., A. Oren, and M. Shilo. 1983. The divalent cation requirement of Dead Sea halobacteria. Arch. Microbiol. 136:184-190.

3. Colwell, R. R., C. D. Litchfield, R. H. Vreeland, L. A. Kiefer, and N. E. Gibbons. 1979. Taxonomic studies of red halophilic bacteria. Int. J. Syst. Bacteriol. 29:379-399.

4. Dussault, H. P. 1955. An improved technique for staining red halophilic bacteria. J. Bacteriol. 70:484-485

5. Gonzalez, C., C. Gutierrez, and C. Ramirez. 1978. Halobacterium vallismortis sp. nov., an amylolytic and carbohydrate-metabolizing, extremely halophilic bacterium. Can. J Microbiol 24:710-715.

6. Grant, W. D., and H. Larsen. 1990. Extremely halophilic archaeobacteria order Halobacteriales ord. nov., p. 2216-2233. In J. T. Staley, M. P. Bryant, N. Pfennig, and J. G. Holt (ed.), Bergey's manual of systematic bacteriology, vol. 3. Williams \& Wilkins, Baltimore, Md.

7. Gutierrez, C., and C. Gonzalez. 1972. Method for simultaneous detection of proteinase and esterase in extremely halophilic bacteria. Appl. Microbiol 24:516-517.

8. Gutierrez, M. C., M. T. Garcia, A. Ventosa, J. J. Nieto, and F. Ruiz-Berraquero. 1986. Occurrence of megaplasmids in halobacteria. J. Appl. Bacteriol. 61:67-71

9. Gutierrez, M. C., A. Ventosa, and F. Ruiz-Berraquero. 1989. DNA-DNA homology studies among strains of Haloferax and other halobacteria. Curr. Microbiol. 18:253-256.

10. Gutierrez, M. C., A. Ventosa, and F. Ruiz-Berraquero. 1990. Deoxyribonucleic acid relatedness among species of Haloarcula and other halobacteria. Biochem. Cell. Biol. 68:106-110.

11. Hartmann, R., H.-D. Sickinger, and D. Oesterhelt. 1980. Anaerobic growth of halobacteria. Proc. Natl. Acad. Sci. USA 77:3821-3825.

12. Hesselberg, M., and R. H. Vreeland. 1995. Utilization of protein profiles for the characterization of halophilic bacteria. Curr. Microbiol. 31:158 162

13. Hilpert, R., J. Winter, W. Hammes, and O. Kandler. 1981. The sensitivity of archaebacteria to antibiotics. Zentralbl. Bakteriol. Parasitenkd. Infektionskr. Hyg. Abt. 1 Orig. Reihe C 2:11-20.

14. Holding, A. J., and J. G. Collee. 1971. Routine biochemical tests. Methods Microbiol. 6A:1-32.

15. Hunter, M. I. S., T. L. Olawoye, and D. A. Saynor. 1981. The effect of temperature on the growth and lipid composition of the extremely halophilic coccus, Sarcina marina. Antonie van Leeuwenhoek 47:25-40.

16. Johnson, J. L. 1994. Similarity analysis of DNAs, p. 655-682. In P. Gerhardt R. G. E. Murray, W. A. Wood, and N. R. Krieg (ed.), Methods for general and molecular bacteriology. American Society for Microbiology, Washington, D.C.

17. Kamekura, M., and M. L. Dyall-Smith. 1995. Taxonomy of the family Halobacteriaceae and the description of two new genera, Halorubrobacterium and Natrialba. J. Gen. Appl. Microbiol. 41:333-350.

18. Kamekura, M., and M. Kates. 1988. Lipids of halophilic archaebacteria, p. 25-54. In F. Rodriguez-Valera (ed.), Halophilic bacteria, vol. 2. CRC Press, Boca Raton, Fla.

19. Kamekura, M., and Y. Seno. 1993. Partial sequence of the gene for a serine protease from a halophilic archaeum, Haloferax mediterranei R4, and nucleotide sequences of 16S rRNA encoding genes from several halophilic archaea. Experientia 49:503-513.

20. Kushner, D. J. 1993. Growth and nutrition of halophilic bacteria, p. 87-103. In R. H. Vreeland and L. I. Hochstein (ed.), The biology of halophilic bacteria. CRC Press, Boca Raton, Fla.

21. Lapage, S. P., P. H. A. Sneath, E. F. Lessel, V. B. D. Skerman, H. P. R. Seelinger, and W. A. Clark (ed.). 1992. International code of nomenclature of bacteria: bacteriological code, 1990 revision. American Society for Microbiology, Washington, D.C

22. Lillo, J. G., and F. Rodriguez-Valera. 1990. Effects of culture conditions on poly- $\beta$-hydroxybutyric acid production of Haloferax mediterranei. Appl. Environ. Microbiol. 56:2517-2521.

23. Mancinelli, R. L., and L. I. Hochstein. 1986. The occurrence of denitrification in extremely halophilic bacteria. FEMS Microbiol. Lett. 35:55-58.

24. McGenity, T. J., and W. D. Grant. 1995. Transfer of Halobacterium saccharovorum, Halobacterium sodomense, Halobacterium trapanicum NRC 34021 and Halobacterium lacusprofundi to the genus Halorubrum gen. nov., as Halorubrum saccharovorum comb. nov., Halorubrum sodomense comb. nov. Halorubrum trapanicum comb. nov., and Halorubrum lacusprofundi comb. nov. Syst. Appl. Microbiol. 18:237-243.

25. Mescher, M. F., J. L. Strominger, and S. W. Watson. 1974. Protein and carbohydrate composition of the cell envelope of Halobacterium salinarium. J. Bacteriol. 120:925-954.

26. Murray, R. G. E., D. J. Brenner, R. R. Colwell, P. De Vos, M. Goodfellow, P. A. D. Grimont, N. Pfennig, E. Stackebrandt, and G. A. Zavarzin. 1990. Report of the Ad Hoc Committee on Approaches to Taxonomy within the Proteobacteria. Int. J. Syst. Bacteriol. 40:213-215.

27. Mylvaganam, S., and P. P. Dennis. 1992. Sequence heterogeneity between the two genes encoding 16S rRNA from the halophilic archaebacterium Haloarcula marismortui. Genetics 130:399-410.

28. Norton, C. F., T. J. McGenity, and W. D. Grant. 1993. Archaeal halophiles (halobacteria) from two British salt mines. J. Gen. Microbiol. 139: 1077-1081.

29. Oren, A., P. Gurevich, R. T. Gemmell, and A. Teske. 1995. Halobaculum gomorrense gen. nov., sp. nov., a novel extremely halophilic archaeon from the Dead Sea. Int. J. Syst. Bacteriol. 45:747-754.

30. Oren, A., and H. G. Trüper. 1990. Anaerobic growth of halophilic archaeobacteria by reduction of dimethylsulfoxide and trimethylamine $N$-oxide. FEMS Microbiol. Lett. 70:33-36.

31. Pecher, T., and A. Bock. 1981. In vivo susceptibility of halophilic and methanogenic organisms to protein synthesis inhibitors. FEMS Microbiol. Lett. 10:295-297.

32. Ross, H. N. M., M. D. Collins, B. J. Tindall, and W. D. Grant. 1981. A rapid procedure for the detection of archaebacterial lipids in halophilic bacteria. J. Gen. Microbiol. 123:75-80.

33. Ross, H. N. M., and W. D. Grant. 1985. Nucleic acid studies on halophilic archaebacteria. J. Gen. Microbiol. 131:165-173.

34. Tindall, B. J. 1992. The family Halobacteriaceae, p. 768-808. In A. Balows, H. G. Trüper, M. Dworkin, W. Harder, and K. H. Schleifer (ed.), The prokaryotes. A handbook of bacteria: ecophysiology, isolation, identification, applications, vol. 1. Springer-Verlag, New York, N.Y.

35. Tomlinson, G. A., and L. I. Hochstein. 1976. Halobacterium saccharovorum 
sp. nov., a carbohydrate-metabolizing, extremely halophilic bacterium. Can J. Microbiol. 22:587-591.

36. Torreblanca, M., F. Rodriguez-Valera, G. Juez, A. Ventosa, M. Kamekura and M. Kates. 1986. Classification of non-alkaliphilic halobacteria based on numerical taxonomy and polar lipid composition, and description of Haloarcula gen. nov. and Haloferax gen. nov. Syst. Appl. Microbiol. 8:89-99.

37. Vreeland, R. H. 1993. Taxonomy of halophilic bacteria, p. 105-134. In R. H.
Vreeland and L. I. Hochstein (ed.), The biology of halophilic bacteria. CRC Press, Boca Raton, Fla.

38. Wayne, L. G., D. J. Brenner, R. R. Colwell, P. A. D. Grimont, O. Kandler, M. I. Krichevsky, L. H. Moore, W. E. C. Moore, R. G. E. Murray, E. Stackebrandt, M. P. Starr, and H. G. Trüper. 1987. Report of the Ad Hoc Committee on Reconciliation of Approaches to Bacterial Systematics. Int. J. Syst. Bacteriol. 37:463-464. 